\title{
Finite Element Modelling of Cyclic Behaviour of Cold-Formed Steel Bolted Moment-Resisting Connections
}

\author{
Peter Fosterl, Gasser Abdelal', James B.P. Lim², Mohammad Hajsadeghi3,4 \\ and ${ }^{*}$ Daniel McCrum ${ }^{5}$
}

Published online: 31 July 2016

To cite this article: Peter Foster, Gasser Abdelal, James B.P. Lim, Mohammad Hajsadeghi and Daniel McCrum. (2016). Finite element modelling of cyclic behaviour of cold-formed steel bolted moment-resisting connections. Journal of Construction in Developing Countries, 21 (1): 167-180. doi: 10.21315/jcdc2016.21.1.9

To link to this article: http://dx.doi.org/10.21315/jcdc2016.21.1.9

Abstract: This paper investigates the accuracy of new finite element modelling approaches to predict the behaviour of bolted moment-connections between cold-formed steel members, formed by using brackets bolted to the webs of the section, under low cycle fatigue. ABAQUS software is used as a modelling platform. Such joints are used for portal frames and potentially have good seismic resisting capabilities, which is important for construction in developing countries. The modelling implications of a two-dimensional beam element model, a three-dimensional shell element model and a three-dimensional solid element model are reported. Quantitative and qualitative results indicate that the threedimensional quadratic S8R shell element model most accurately predicts the hysteretic behaviour and energy dissipation capacity of the connection when compared to the test results.

Keywords: Cold-formed steel, Bolted connection, Finite element modelling, Cyclic performance, Energy dissipation

\section{INTRODUCTION}

In statically loaded structures, such as portal frame buildings structures, typical bolted moment-connections between cold-formed steel channel-sections can be formed through brackets bolted to the webs of the cold-formed steel sections being connected (see Figure 1). Such portal frame structures have numerous applications in developing countries for lost cost housing and shelter; they also potentially have good seismic resisting capabilities. Previous research under monotonic load (Lim and Nethercot, 2003; Lim et al., 2014) has shown that the limit of strength of the channel-section is due to failure caused by a bi-moment in the section (see Figure 2), and also influenced by the length of the bolt-group. A full review of this and other related work is described in Wrzesien, Lim and Nethercot (2012).

However, in earthquake loading situations, bolted moment-connections between cold-formed steel channel-sections are subject to cyclic loading, typically lasting between 60 to 120 seconds, under a relatively low number of

ISchool of Mechanical and Aerospace Engineering, Queen's University of Belfast, UNITED KINGDOM 2Department of Civil and Environmental Engineering, University of Auckland, NEW ZEALAND

${ }^{3}$ School of Engineering Sciences, University of Liverpool, UNITED KINGDOM

${ }^{4}$ Civil Engineering Department, Xian Jiaotong-Liverpool University, CHINA

${ }^{5}$ School of Planning, Architecture and Civil Engineering, Queen's University of Belfast, UNITED KINGDOM

*Corresponding author: d.mccrum@qub.ac.uk 
deformation cycles. To investigate the behaviour of such connections under such seismic cyclic action, cyclic displacement-based experiments should be adopted, as per Section S6.2 of American Institute of Steel Construction (AISC) Seismic Provision (American National Standards Institute [ANSI]/AISC 341, 2005). Section S6.2 specifically refers to the cyclic qualification of moment resisting connections in special and intermediate moment frames (ANSI/AISC 341, 2005). These are a standard form of repeatable test, used to understand the low cycle behaviour of structural elements or connections. The loading cycles used in the numerical analysis in this paper are shown in Figure 3 and are the same as that used by Sabbagh et al. (2012a).

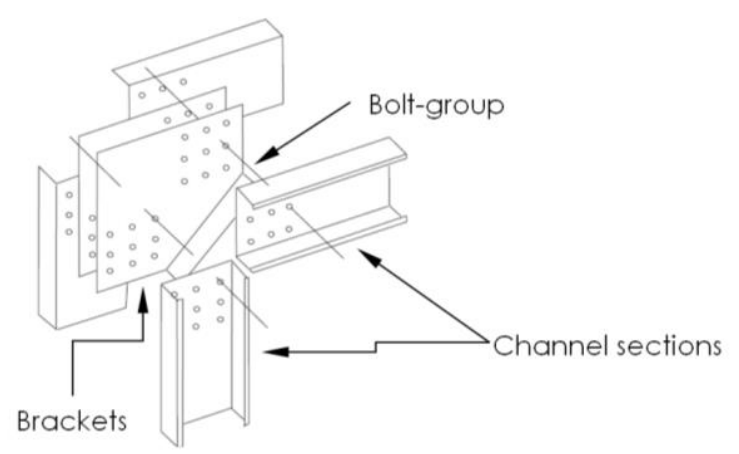

Figure 1. Typical Details of a Cold-Formed Steel Bolted-Moment Connection

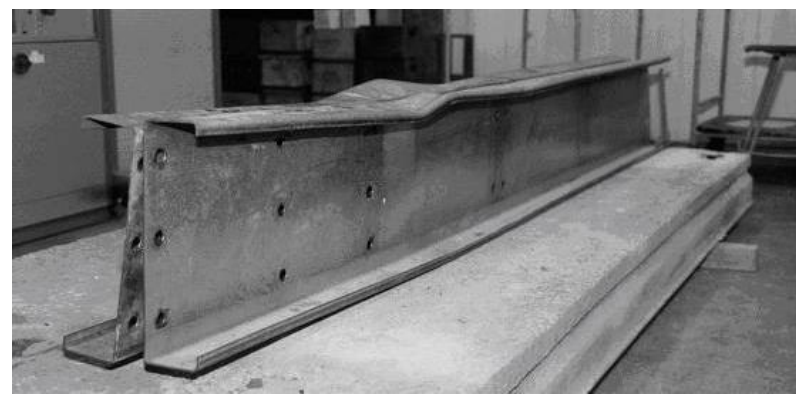

Figure 2. Failure in Channel-Sections as Influenced by the Length of the Bolt-Group (Lim and Nethercot, 2003)

Typically, these tests are conducted at pseudo-static rates of loading, such that strain rate effects are not considered. Therefore, the rate of loading does not influence the mechanical properties and allows plasticity to spread beyond the point of initiation. The moment-rotation or load-deformation hysteresis of a bolted connection is used to evaluate the ductility and energy dissipation capacity of the specimen under investigation.

168/PENERBIT UNIVERSITI SAINS MALAYSIA 


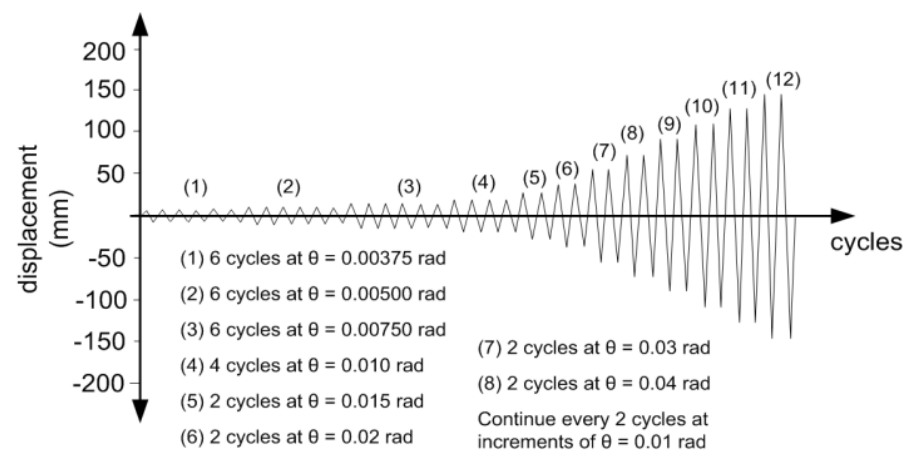

Figure 3. Load Cycles Used in Testing by Sabbagh et al. (2012a) According to ANSI/AISC 341 (2005)

In earthquake engineering, the principle of dependable controlled inelastic deformation is fundamental to providing structures that perform safely (European Committee for Standardisation, 2004; Elghazouli, 2009). Earthquake resistant structures are designed to deform inelastically during moderate to large earthquake events as it is not practical/cost effective to design a structure to remain elastic during such events. In multi-storey buildings, concentration of inelastic demand into the columns must be avoided, requiring a strong column and weak beam design principle to be maintained throughout the range of expected inelastic deformation. At beam-column connections, plastic hinges are allowed to form in the beam but not within the column. Yielding and subsequent formation of plastic hinges dissipate energy induced in the structure as a result of inertial forces. The predictable dissipation of energy and the ability to develop dependable strength under repeated cycles of inelastic loading are fundamental in ensuring predictable damage and life safety. In this paper one of the parameters used to define seismic performance is the displacement ductility demand:

$$
\mu=\frac{\delta_{u}}{\delta_{y}}
$$

where $\delta_{u}$ is the maximum displacement of the structure and $\delta_{y}$ is the first yield displacement of the structure. Interstorey drifts are also used in design as they relate to the protection of the building envelope whereas ductility demand relates to control of structural damage.

Limited research has been undertaken to quantify the cyclic or seismic performance of cold-formed steel moment resisting connections in earthquake engineering. Recently, Sabbagh (2011) and Sabbagh et al. (2011; 2012a; 2012b; 2013) have conducted a combination of experimental and non-linear elastic plastic finite element analysis on novel back-to-back curved-flange cold-formed steel moment resisting connections (see Figure 4). 
(a)

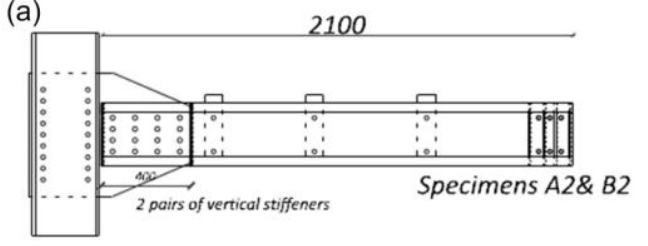

(b)

720

(c)

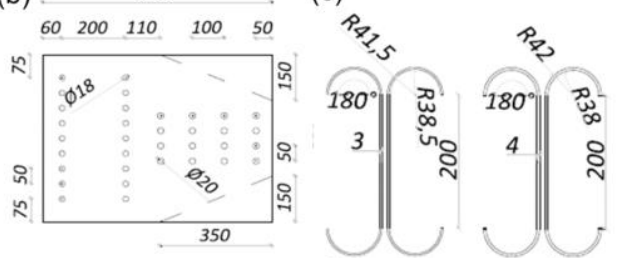

Through plate Beam sections

$\overline{t=8 m m(A 1-3) ~} t=10 \mathrm{~mm}(B 1-3) \quad t=3 \mathrm{~mm}$ (A1-3) $t=4 m m(B 1-3)$

Figure 4. Details of Curved Flange Beams Cyclically Tested by Sabbagh et al. (2013): (a) Elevation of Test Specimen, (b) Details of Through Plate and (c) Section Through Back-To-Back Beams

In this paper, numerical models of varying degrees of complexity were used to simulate the cyclic displacement response of curved-flange channel-sections as tested by Sabbagh et al. (2012a). Models using both linear and quadratic solid and shell elements were considered. Importantly, this research extends existing modelling understanding of bolted moment connections by explicitly modelling the bolted connections in 3-D finite element models. Results show that quadratic shell elements with explicitly modelled bolted connections, capture the cyclic behaviour of cold-formed steel moment connections most accurately. An improved understanding of the behaviour of such connections is important in order for structures using such connections to be adopted, in particular in developing countries in seismic sensitive areas.

\section{MATERIAL PROPERTIES}

The value of Young's modulus and Poisson's ratio used for cold-formed steel were $210 \mathrm{kN} / \mathrm{mm}^{2}$ and 0.3, respectively. As per Sabbagh et al. (2013), the yield stress was $308 \mathrm{~N} / \mathrm{mm}^{2}$ and the ultimate stress was $474 \mathrm{kN} / \mathrm{mm}^{2}$. The maximum principal stress was assumed to be $10 \%$ higher than the yield stress (i.e. $338.8 \mathrm{~N} / \mathrm{mm}^{2}$ ). The material model assumed was a bilinear plasticity model with isotropic strain hardening as per the coupon tests of Sabbagh et al. (2013).

\section{NUMERICAL MODELLING}

The beam-column connections have been modelled and analysed using ABAQUS (ABAQUS ver. 6.11, 2011). Beam-column and continuum finite element approaches were adopted in this paper to demonstrate their applicability towards 
accurately capturing the cyclic response of cold-formed steel curved channel section moment resisting connections. Two-dimensional beam-column models, three-dimensional plate element models and three-dimensional solid element models were all investigated. In structures subjected to low cycle fatigue, and in sections subjected to high stress concentrations, the potential for cracks to develop is high. Therefore the applicability of the eXtended Finite Element Method (XFEM) for crack analysis was also investigated. However, it was found that once a crack began to initiate in an element the numerical analysis failed to converge. The premature failure of the numerical analysis meant the cyclic capacity of the connection was not fully captured. For this reason, the authors therefore recommend not using XFEM in cyclic or dynamic analysis of cold-formed sections.

For reference, the analysis parameters used are detailed below. The Cohesive Surface Crack Method of crack propagation was selected in this analysis to model the cohesive behaviour response in the enriched XFEM elements. The maximum principal stress failure criterion was selected for damage initiation. Damage was defined by a mixed-mode energy based BenzeggaghKenane damage evolution criterion (Benzeggagh and Kenane, 1996). The damage was defined with power law damage propagation input parameters as recommended in Simulia (ABAQUS ver. 6.11, 2011) with a power equal to 2.284 and a viscosity coefficient to stabilise the damage equal to $1 \times 10^{-5}$. The normal and shear mode fracture energy are both required for the XFEM analysis. The normal mode fracture energy (Mode 1) was calculated using the fracture toughness of $60 \mathrm{~kJ} / \mathrm{m}^{2}$ (Ashby and Jones, 1996). The shear mode fracture energy in the first and second directions (Modes 2 and 3) were assumed to be the same.

\section{DETAILS OF FINITE ELEMENT IDEALISATION}

Figure 5 presents the details of the curved flange beams tested by Sabbagh et al. (2012a) where the same cross-section was adopted in this study. The thickness of the cross-section for the analysis is $4 \mathrm{~mm}$ as per Specimen Bl of Sabbagh et al. (2012a).

Details of the finite element idealisations are shown in Figure 5. The vertical lines at one-third distance along the beam (see Figures 5[b] and 5[c]) indicate the locations of out-of-plane restraint provided during the test. Four different idealisations were considered:

1. Idealisation 1 (ID-1): 1-D BEAM element idealisation assuming fully fixed-end support (see Figure 5[a]).

2. Idealisation 2 (ID-2): 3-D SHELL element idealisation assuming fully fixed end support (see Figure 5[b]).

3. Idealisation 3 (ID-3): 3-D SHELL element idealisation with bolted connection modelled (see Figure 5[c]).

4. Idealisation 4 (ID-4): 3-D SOLID element idealisation with bolted connection modelled (ID-4) (see Figure 5[C]). 

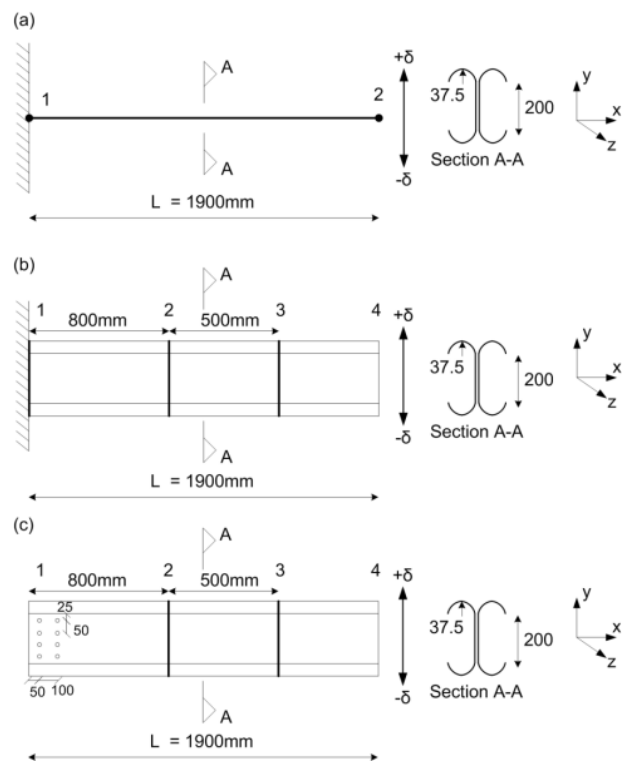

Figure 5. Idealisations for Moment Resisting Connection Cantilever for (a) 1-D Idealisation with Fixed End Support, (b) 3-D Idealisation with Fixed End Support and (c) 3-D Idealisation with Bolted Connection Support

\section{Idealisation of Bolted Moment Connection}

ID-3 and ID-4 both require the bolts to be idealised. Including both the bolts and bolt-holes in the finite element model would greatly increase the computational time, as the deformation of both the bolt-holes and bolts would then need to be captured. Instead, the nodes at the center of each bolt-hole were restrained in the out-of-plane direction. The elongation of the holes in the two in-plane directions was captured through the use of two non-linear spring elements, $k_{s x}$ and $k_{\text {sy. }}$. Figure 6 shows details of the restraints and springs.

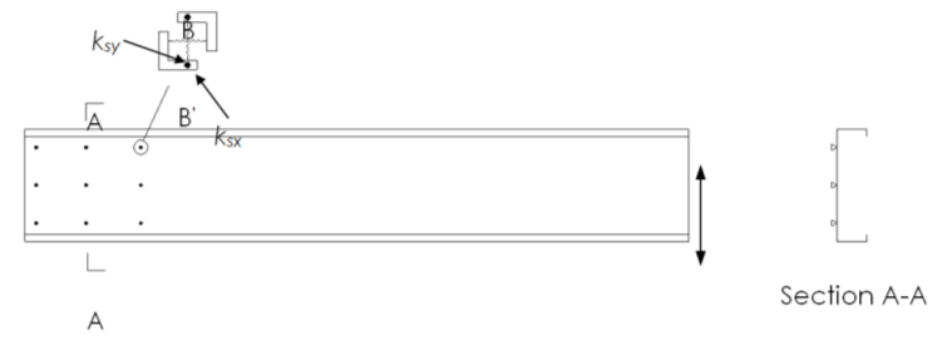

Figure 6. Details of Finite Element Idealisation of Bolted Connection

Notes:

1. Nodes B and B' are coincident.

2. Node $B$ is attached to the channel-section.

3. Node $B^{\prime}$ is fixed in all three global directions.

4. The stiffness of the springs connecting each pair of coincident nodes are as follows: $k_{s x}=k_{s y}=k_{b}$

172/PENERBIT UNIVERSITI SAINS MALAYSIA 
The stiffness $k_{s x}$ and $k_{s y}$ were assumed to be $30 \mathrm{kN} / \mathrm{mm}$. It should be noted that although the spring stiffness of $30 \mathrm{kN} / \mathrm{mm}$ is realistic, the ultimate load of the joints is insensitive to the value of the stiffness within the realistic range, say, 10 $\mathrm{kN} / \mathrm{mm}$ to $100 \mathrm{kN} / \mathrm{mm}$. It is important that a realistic stiffness is modelled, and not one set to infinity, as would be the case of fixing the node in the $x$ - and $y$ directions.

\section{DETAILS OF THE FINITE ELEMENT MESH}

\section{Beam Mesh}

Both channel-sections were used to determine the gross section properties to be used in the beam idealisation. The length of each beam element was $150 \mathrm{~mm}$ with material properties and cross-section defined.

\section{Shell and Solid Element Mesh}

Figure 7 shows details of the finite element mesh refinement for one of the coldformed steel channel sections. Four elements were used through the thickness of the thin wall plates. The size of the shell elements is $5 \times 5 \mathrm{~mm}$ at the fixed end. This gradually increases to $20 \times 20 \mathrm{~mm}$ at the free end. The back-to-back channelsections were modelled with a gap of $3 \mathrm{~mm}$ between them. The finite element mesh used for the solid elements was the same as for the shell elements. The elements were modelled using large strain elements that linearly (S4R) and quadratically (S8R) interpolate the displacement functions.

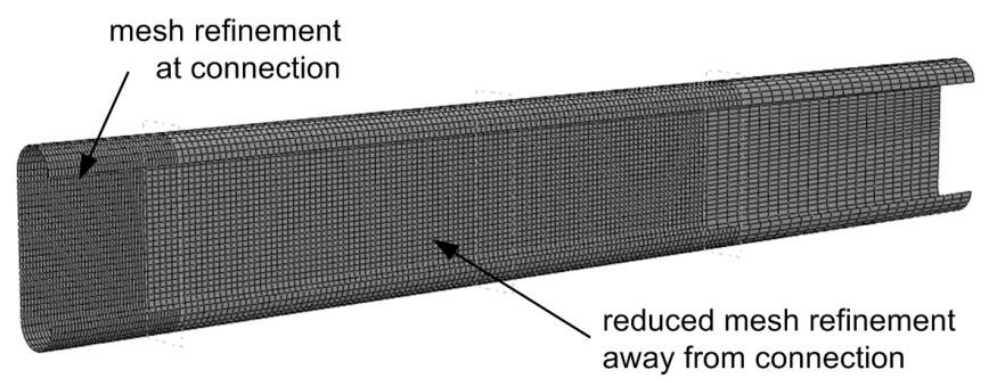

Figure 7. Details of Finite Element Mesh of Single Curved Flange Section with FixedEnd Connection

\section{FINITE ELEMENT RESULTS}

\section{Comparison of Analyses}

Table 1 presents a summary and comparison of the key results from the numerical analyses performed. As expected, ID-1 overestimates both the cantilever tip displacement at first yield $(33.8 \%)$ and initial stiffness $(60.2 \%)$. The energy dissipation was underestimated by $98 \%$ due to the analysis failing prematurely during the 5 th 
cycle group (see Table 1 and Figure 8a). The ID-1 model provides a poor estimate of the cyclic performance of the moment resisting connection. As mentioned previously, the purpose of the beam idealisation is to provide a benchmark for the shell and solid idealisations.

Analysis of Table 1 and Figures 8 and 9 shows that the shell analyses using linear and quadratic elements overestimated the initial stiffness, whilst the bolted connection using linear and quadratic elements underestimated the initial stiffness. Figure 8(b) shows the hysteresis plot for the Linear ID-2 analysis. Unlike the hysteresis plot in Figure 10; it can be seen that the stiffness reduces notably after peak force capacity of the member is reached. The Linear ID-3 model underestimates the initial stiffness $(71 \%)$ of the test specimen resulting in a larger amount of stiffness softening than the Linear ID-2 analysis. The influence of the bolted connections compared to the fixed-end connection can be seen comparing the hysteresis plots in Figures $8(b)$ and $8(c)$.

The Linear ID-2 model response was dominated by local buckling as shown in Figure $8(\mathrm{~b})$. On the other hand, the explicit modelling of the bolted connection can be seen to dominate the hysteretic response in the Linear ID-3 model as shown in Figure 8(c). The Linear ID-4 hysteresis in Figure 8(d) shows an idealised strain hardening response that fails to capture local buckling. First yield was predicted more accurately by the quadratic element models (4.4\% average error to test results) as compared to the shell element models (average $28.6 \%$ error) indicating that the solid elements do not capture local buckling.

The influence of the bolted and fixed-end connection can be seen in the quadratic element models as shown in Table 1 and Figure 9. As expected, the initial stiffness of the idealised ID-2 compared to the ID-3 is considerably stiffer (79.8\% greater initial stiffness). The hysteresis plot in Figure 9 (c) represents the most similar response to the test specimen in Figure 10. The initial stiffness and total energy dissipation are underestimated; however the quadratic ID-4 model has captures the peak load, local buckling, initial yield and ductility most closely to the test specimen. Sabbagh et al. (2013) observed that the response of the specimen was dominated by connection slip rather than rotational behaviour in the beam.

Figure 11 shows the von Mises stress plots for each of the finite element idealisations at their peak displacement. No magnification factor is applied. Figure 11 (b) shows significant local buckling of the flanges away from the end fixity for the quadratic ID-2 analysis. The quadratic ID-4 analysis in Figure 11 (c) also shows some local buckling of the flanges as a result of the compressive load together with the bi-moment in the out-of-plane direction. Most importantly though, the quadratic ID-3 analysis captures web buckling similar to that observed during the test in Figure 12(b). 


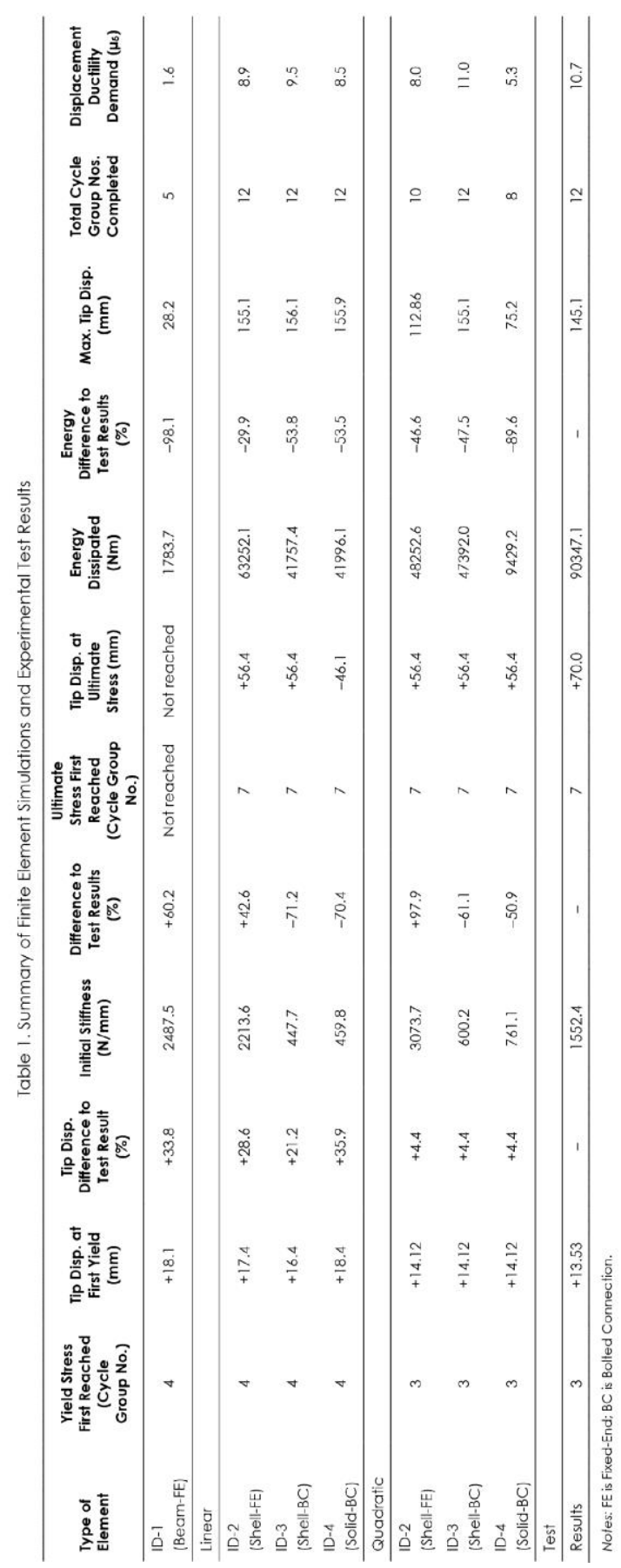

PENERBIT UNIVERSITI SAINS MALAYSIA/175 
Energy dissipation is an important design principal in seismic design as inelasticity is used in design to ensure a safe and predictable response during a seismic event. It can be seen from Table 1 that the hysteretic energy dissipated in the moment resisting connection during the beam analysis and others varies significantly. The reasons for this are that distortion and local buckling of the section was not taken into consideration during the ID-1 analysis. The beam analysis has failed prematurely due to excessive mesh distortion as it is not capable of analysing the significant deformations as plane sections remain plane. The Linear ID-2 analysis provides the most accurate measure for total energy dissipated, however in general the energy dissipation is underestimated by the models. One of the main reasons for this is the difficulty in accurately capturing the stiffness using finite element analysis. Another reason for this is the test displacement cycles were paused at a number of times during the test resulting in an excessive measure of area under the hysteresis curve. Also, the displacement control by the test apparatus did not completely match the input displacement cycles as per Figure 3. Therefore, the displacement cycles defined and assigned onto the finite element models was different to the test.

The displacement ductility demand provides an indicator of the level of inelastic deformation that the moment resisting connection is capable of resisting. As can be seen from Table 1, the ID-1 and quadratic ID-4 analyses failed prematurely and therefore incorrectly indicate low levels of ductility demand. The quadratic and linear ID-2, ID-3 and ID-4 analyses all have similar levels of ductility demand and are similar to that recorded during the test.

Sabbagh et al. (2011) modelled the experiments in ABAQUS using threedimensional S8R elements (eight noded quadratic shell elements) with a mesh sensitivity of $20 \mathrm{~mm}$ and end nodes fully fixed in all six degrees of freedom. Initially, Sabbagh et al. (2011) did not investigate the modelling of the bolted connection, but in more recent work (Sabbagh et al., 2013) the bolted connections were modelled using connector elements to connect the beams to the supporting plate. The methodology presented in this paper for modelling the bolted connection has been verified previously (Lim and Nethercot, 2004) and describes a simpler method of modelling bolts as to that of Sabbagh et al. (2013): the two methods, however, should provide the same overall result. 
(a)

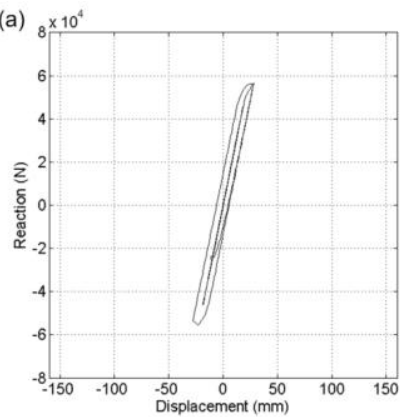

(c)

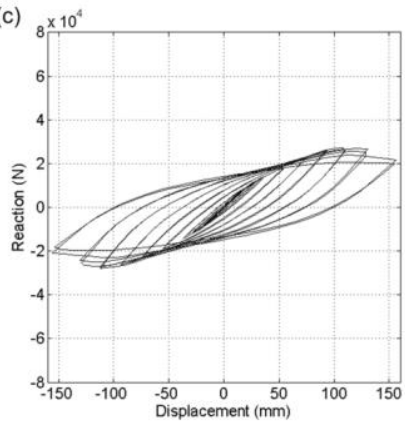

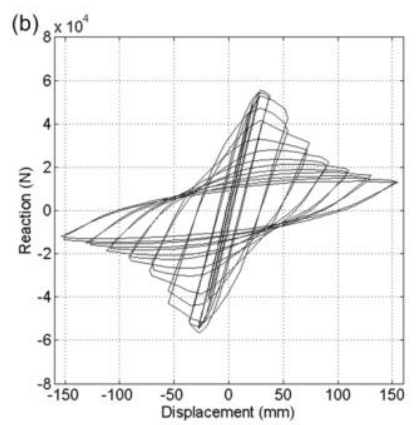

(d)

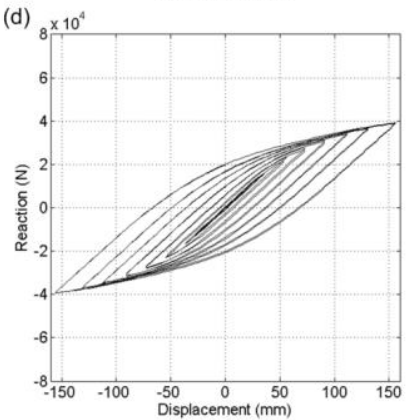

Figure 8. Hysteresis Plot for Cantilever Beam Analysed Using (a) ID-1, (b) Linear ID-2, (c) Linear ID-3 and (d) Linear ID-4
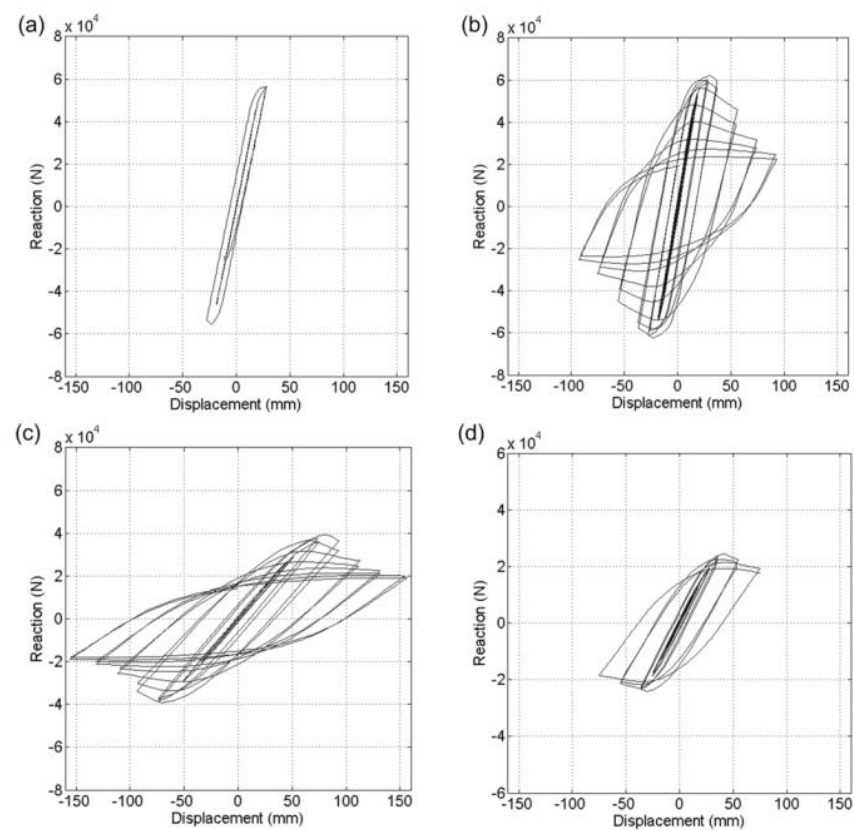

Figure 9. Hysteresis Plot for Cantilever Beam Analysed Using (a) ID-1, (b) Quadratic ID-2, (c) Quadratic ID-3 and (d) Quadratic ID-4 
Peter Foster et al.

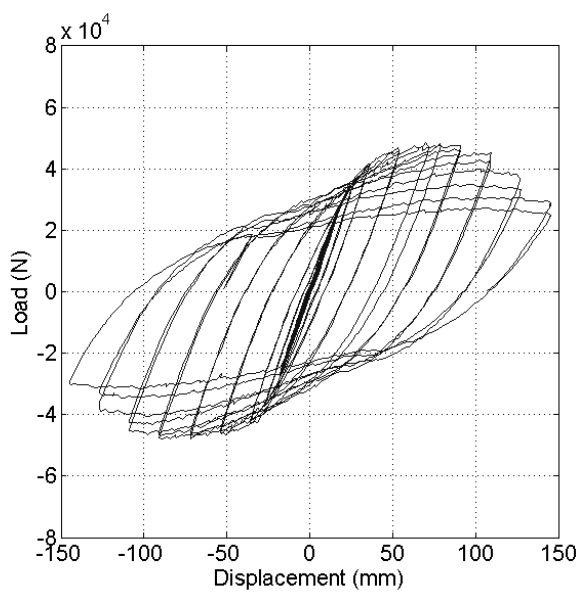

Figure 10. Load vs. Deflection Hysteresis Curve of Specimen Bl from Sabbagh et al. (2012a)
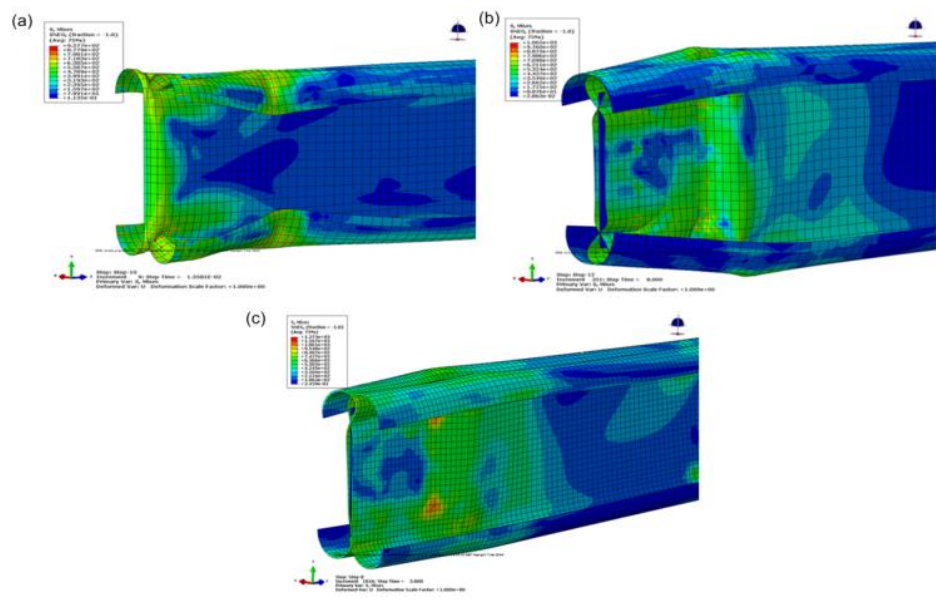

Figure 11. Deformed Shape of Von Mises Stress Plot of Back to Back Curved Flange Cold Rolled Steel Cantilever Beam at the Peak Displacement during the Final Cycle (Deformation Scaling Factor 1.0) for (a) Quadratic ID-2, (b) Quadratic ID-3 and (c) Quadratic ID-4 (No Magnification) 
(a)

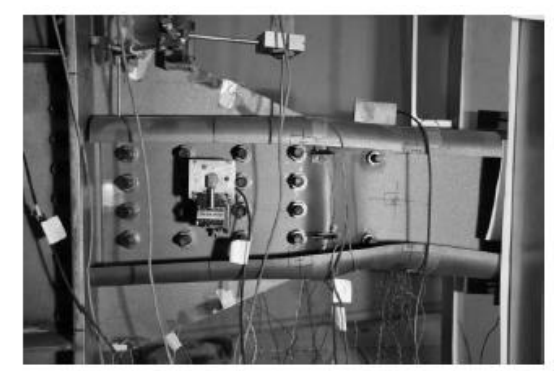

(b)

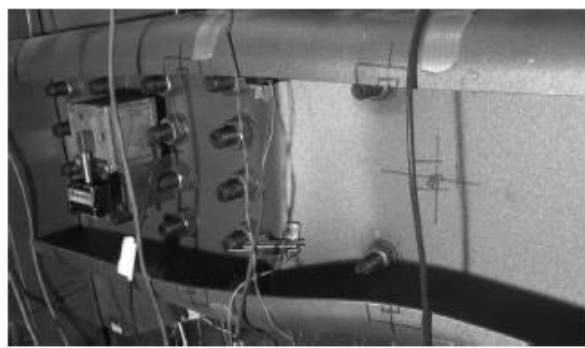

Figure 12. Photographs of Tested Specimen B2 by Sabbagh et al. (2012a): (a) Elevation and (b) Skewed Elevation, Indicating Web Flange Buckling at Final Cycle

\section{CONCLUSIONS}

A numerical investigation was undertaken to accurately model the cyclic behaviour of a bolted cold-formed steel moment resisting connection. Numerical analyses of varying complexity were compared to test results published in the literature. A simplistic one-dimensional beam element analysis was followed by more sophisticated three-dimensional shell and solid element analyses. Both fullyfixed and explicitly modelled bolted connections were investigated.

The results showed, as expected, that the beam element did not capture cyclic behaviour accurately. The three-dimensional solid element analyses also did not capture local buckling and therefore has captured the hysteretic behaviour poorly. Neither the beam-column nor solid element analyses shall be used to evaluate the cyclic behaviour of cold-formed steel moment resisting connections.

Quadratic and linear S4R elements were compared with quadratic S8R elements, capturing the local buckling during cyclic loading more accurately. The most accurate model to capture the cyclic behaviour of the cold-formed steel moment connection is shell quadratic S8R elements with explicitly modelled bolted connections using spring elements.

The use of such connections for portal frame structures would have numerous applications for shelter and housing in developing countries. Further research to quantify the behaviour of such structures is needed.

\section{ACKNOWLEDGEMENT}

The Authors would like to acknowledge the support provided by Queen's University Belfast, through a Department of Employment and Learning Scholarship.

\section{REFERENCES}

ANSI/AISC 341. (2005). Seismic Provisions for Structural Steel Buildings. Illinois, US: American Institute of Steel Construction (AISC). 
Ashby, M.F. and Jones, D.R.H. (1996). Engineering Material 1: An Introduction to Their Properties and Applications. 2nd Ed. Oxford: Butterworth-Heinemann Ltd.

Benzeggagh, M.L. and Kenane, M. (1996). Measurement of mixed-mode delamination fracture toughness of unidirectional glass/epoxy composites with mixed-mode bending apparatus. Composites Science and Technology, 56(4): 439-449. doi: 10.1016/0266-3538(96)00005-X.

Dassault Systèmes. (2011). ABAQUS Standard User's Manual. Version 6.11-1. Providence, RI: Dassault Systèmes.

Elghazouli A.Y. (2009). Seismic Design of Buildings to Eurocode 8. Oxon, UK: Spon Press.

European Committee for Standardisation (CEN). (2004). EN 1998-1: Eurocode 8: Design of Structures for Earthquake Resistance, Part 1: General Rules, Seismic Actions and Rules for Buildings. Brussels: CEN.

Lim, J.B.P., Hancock, J., Clifton, G.C. and Pham, C.H. (2014). Direct strength method for ultimate strength of bolted moment-connections between coldformed steel channel members. Proceedings: 22nd International Specialty Conference on Cold-Formed Steel Structures. St. Louis, Missouri, US: The Center for Cold-Formed Steel Structures, 729-744.

Lim, J.B.P. and Nethercot, D.A. (2004). Finite element idealization of a cold-formed steel portal frame. Journal of Structural Engineering, 130(1): 78-94. doi: 10.1061/(ASCE)0733-9445(2004)130:1 (78).

. (2003). Ultimate strength of bolted moment: Connections between coldformed steel members. Thin-Walled Structures, $41(11)$ : 1019-1039. doi: 10.1016/S0263-8231 (03)00045-4.

Sabbagh, A.B. (2011). Cold-formed steel elements for earthquake resistant moment frame buildings. PhD diss. University of Sheffield.

Sabbagh, A.B., Petkovski, M., Pilakoutas, K. and Mirghaderi, R. (2013). Cyclic behaviour of bolted cold-formed steel moment connections: FE modelling including slip. Journal of Constructional Steel Research, 80: 100-108. doi: 10.1016/j.jcsr.2012.09.010.

. (2012a). Development of cold formed steel elements for earthquake resistant moment frame buildings. Thin-Walled Structures, 53: 99-108. doi: 10.1016/j.tws.2012.01.004.

. (2012b). Experimental work on cold-formed steel elements for earthquake resilient moment frame buildings. Engineering Structures, 42: 371-386. doi: 10.1016/j.engstruct.2012.04.025.

. (2011). Ductile moment-resisting frames using cold-formed steel sections: An analytical investigation. Journal of Constructional Steel Research, 67(4): 634-646. doi: 10.1016/j.jcsr.2010.11.016.

Wrzesien, A., Lim, J.B.P. and Nethercot, D.A. (2012). Optimum joint detail for a general cold-formed steel portal frame. Advances in Structural Engineering, 15(9): 1623-1640. doi: 10.1260/1369-4332.15.9.1623.

180/PENERBIT UNIVERSITI SAINS MALAYSIA 